\title{
On the dehydration of sulphate of lime under various circumstances
}

\author{
M.M.E. Millon
}

To cite this article: M.M.E. Millon (1847) On the dehydration of sulphate of lime under various circumstances, Philosophical Magazine Series 3, 30:201, 299-301, DOI: $10.1080 / 14786444708645700$

To link to this article: http://dx.doi.org/10.1080/14786444708645700

册 Published online: 30 Apr 2009.

Submit your article to this journal $[\pi$

Џll Article views: 2

Q View related articles $₫$ 


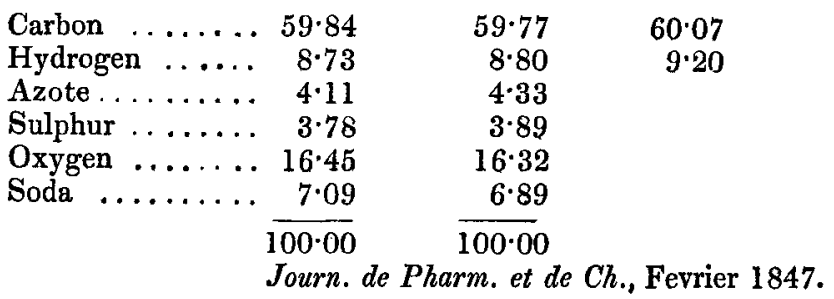

SINGULAR PROPERTY OF GUN-COTTON MIXTURE.

Dr. Draper has made the following observations:-Lecturers on chemistry have known for a long time, that one of the best methods of illustrating the properties of carbonic acid gas, is to evolve it from carbonate of ammonia by the action of monohydrated nitric acid. A dense white fume accompanies the gas, and marks all its movements in a striking manner.

Commercial nitric acid fails to produce the same effect. It sets the gas free in an invisible state. But if a mixture of commercial nitric acid and oil of vitriol be used, then the dense fume is at once produced. The explanation seems to be, that the oil of vitriol, by retaining water, allows some of the carbonate of ammonia to pass off with the carbonic acid in a dry state, and hence gives the gas a smoky aspect.

But it is singular, that though oil of vitriol will of course decompose carbonate of ammonia very rapidly, the gas which escapes is transparent.

Some months ago Dr. Ellet, of South Carolina College, published a process for preparing gun-cotton, which is unquestionably the greatest improvement yet made in the preparation of that explosive substance. His plan is to soak cotton in a mixture of oil of vitriol and saltpetre, and then wash it thoroughly from the adhering salt. Now if this mixture of oil of vitriol and saltpetre be made to act on carbonate of ammonia, like monohydrated nitric acid, or common nitric acid mixed with sulphuric, it evolves carbonic acid in the smoky state.

\section{ON THE DEHYDRATION OF SULPHATE OF LIME UNDER VARIOUS CIRCUMSTANCES. BY M. M. E. MILLON.}

The author observes that it is well-known that sulphate of lime which is slowly produced, retains its water of combination at a temperature at which precipitated sulphate loses it.

Sulphate of lime.-This salt contains two equivalents of water, $\mathrm{SO}^{3}, \mathrm{HO}+\mathrm{CaO}, \mathrm{HO}$; according to Graham it suffers no loss at $212^{\circ} \mathrm{F}$.; and becomes anhydrous at $266^{\circ}$. The general results obtained by M. Millon effect considerable changes in this statement.

Sulphate of lime, of whatever form, origin or mode of formation, always suffered a first loss, varying from 15 to 17 per cent. This quantity represents 1.5 equivalent of water : its elimination is per- 
fectly decided, and cannot be confounded with the total loss, which varies from 20 to 22 per cent. and corresponds to two equivalents of water. The following are the results of experiments :-

Artificial sulphate of lime, prepared by precipitating cold solutions of sulphate of zinc and chloride of calcium; when dried over sulphuric acid the result was invariable. By exposure for six hours to a temperature of $176^{\circ}$ to $185^{\circ} \mathrm{F}$. it lost 17 per cent. ; no further loss occurred by exposure for an additional hour to the same temperature; when rendered perfectly anhydrous the loss was 22 per cent.

Artificial sulphate of lime, precipitated from mixed boiling solutions of sulphate of zinc and chloride of calcium; dried as before, the loss at $176^{\circ}$ to $185^{\circ} \mathrm{F}$. remained invariably at 15.71 per cent.; when rendered anhydrous the loss was $20 \cdot 87$ per cent.

Moistened plaster lost at the above temperatures 16.22 per cent. ; rendered anhydrous, the loss was $20 \cdot 39$ per cent.

Precipitated sulphate of lime, dissolved in hydrochloric acid, and crystallized from it.-By fifteen hours' exposure to $176^{\circ}$ up to $185^{\circ}$, it lost no weight, and none occurred till the temperature reached $221^{\circ} \mathrm{F}$., when it lost $15 \cdot 38$ per cent. The same heat was afterwards continued during four hours without further loss. Rendered anhydrous, the loss was 20.78 per cent.

Arrow-headed gypsum from Montmartre.-This suffered no loss at $176^{\circ}$ to $185^{\circ}$ F.; at $221^{\circ}$ it amounted to 15.37 per cent., and the total loss was $20^{\circ} \cdot 78$ per cent.

Fibrous sulphate of lime.-In fifteen hours lost no weight at $185^{\circ} \mathrm{F}$; at $221^{\circ}$ the loss was $17 \cdot 60$ per cent.; it was afterwards exposed for twelve hours to the same temperature with scarcely any diminution; the total loss was $22 \cdot 62$ per cent.

Alabaster from Volterra.-Suffered no diminution of weight by exposure at $176^{\circ}$ to $185^{\circ} \mathrm{F}$; at $230^{\circ} \mathrm{F}$. the loss was $15^{\circ} 61$ per cent.; several hours' continued application of the same heat occasioned no further diminution of weight; the total loss was 20.83 per cent.

Snow-white gypsum (Gypse en niege).- - Lost no weight at $185^{\circ} \mathrm{F}$; at $238^{\circ} \mathrm{F}$. it was 15.57 per cent. No further diminution occurred by several houre' longer exposure to this heat. The total loss was $21 \cdot 27$ per cent.

Fibrous gypsum from America.-Lost no weight at $185^{\circ} \mathrm{F}$.; at $230^{\circ} \mathrm{F}$. lost 15.41 per cent.; total loss 20.59 per cent.

Prismatic gypsum from Sicily. - No diminution of weight at $185^{\circ} \mathrm{F}$.; at $230^{\circ}$ it was 15.58 per cent., and the total loss was $20^{\circ} 44$ per cent.

It appears, therefore, that all native sulphates of lime retain their water at $185^{\circ} \mathrm{F}$, and do not lose any below $221^{\circ}$ to $236^{\circ}$. Artificial sulphate of lime crystallized in hydrochloric acid is similarly circum. stanced. Artificial sulphate of lime, on the other hand, whether precipitated hot or cold, loses three-fourths of the water at $176^{\circ}$ to $185^{\circ}$. Moistened plaster is also dehydrated at this lower temperature.

It will be observed that all the sulphates of lime undergo a fractional loss of water, and that the second state of hydration is ex. pressed by $\left(\mathrm{SO}^{3}\right)^{2}, \mathrm{HO}+2 \mathrm{CaO}$. 
The last fourth of the water of hydration goes off very slowly, if the heat be not raised to nearly $400^{\circ}$ or $570^{\circ} \mathrm{F}$.; at $257^{\circ}$ to $393^{\circ} \mathrm{F}$. mere traces of water are separated in several hours. This resistance is unquestionably very favourable to the calcination of plaster intended for buildings; it prevents its complete dehydration, even at a somewhat higher temperature.

M. Millon has alsu observed that anhydrates which contain some hundredths of water, lose it in fractional quantities; one specimen lost 3.65 per cent. of water. The first loss of $2 \cdot 89$ per cent. occurred at $221^{\circ} \mathrm{F}$.; the remainder, or 0.76 per cent. of water, required a higher temperature for its expulsion. On examining the anhydrate with a glass, opake portions were visible, which were small crystals of the trapezoidal variety of sulphate of lime, and were evidently formed by the anhydrate having absorbed moisture from the atmosphere.-Ann, de Chim. et de Phys., Fevrier 1847.

\section{COFFEE AS AN ANTIDOTE TO aCETATE OF MORPHIA.}

An invalid took at one dose ten grains and nearly eight-tenths of acetate of morphia; thirty grains of emetic tartar were exhibited without occasioning vomiting; after a lapse of three hours, and not till then, and when the patient was perfectly comatose, a strong infusion of coffee with the grounds was given. In the course of twelve hours the invalid took about $11 \frac{1}{2}$ ounces of coffee; the coma ceased and he recovered.

This fact proves, among a lundred others, that even in the worst cases of poisoning, the medical man should never despair of the recovery of his patient. In the above-described case, in spite of a very strong dose of poison, and notwithstanding the absence of all assistance during tliree entire hours, and although it was impossible to evacuate any portion of the morphia, the patient recovered. If a similar accident shonld again occur,vomiting ought to be immediately attempted; if this fail the stomach-pump should be employed, and then concentrated coffee should be administered.-Journ. de Pharm. et de Ch., Fevrier 1847.

\section{ON THE FORMATION OF CYLINDIRICAL MASSES OF SNOW IN ORKNEY.}

\section{To Richard Taylor, Esq.}

Sandwick Manse by Stromness, Feb. 11, 1847.

My dear Sir,-A curious phænomenon in this parish has astonished and perplexed all, and filled the superstitious with no small degree of consternation. Since the 6 th inst. we have had hail- or snow-showers, on the 9th snow-drift, and yesterday a slight thaw with frost again in the evening.

During the night a heavy fall of snow took place which covered the plain to the depth of several inches. Upon this pure carpet there rest thousands of large masses of snow which contrast strangely with its smooth surface. A solitary mass may be seen in a field, but in general they occur in patches from one acre to a hundred in extent, while the clusters may be half a mile asunder, and not one mass to 